\title{
Effect of Arch Support on Prevention of Foot Pain During Pregnancy
}

\author{
MOHAMED A. AWAD, Ph.D.*; AFAF M. BOTLA, Ph.D.*; ABD EL-HAMID A. ATTA ALLAH, M.D.** and \\ SARA A. AMR, M.Sc.* \\ The Department of Physical Therapy for Obstetrics and Gynaecology, Faculty of Physical Therapy, Cairo University* and \\ The Department of Orthopaedic Surgery, Faculty of Medicine (Girls), Al-Azhar University**, Egypt
}

\begin{abstract}
Background: During pregnancy women experience several changes in the body's physiology, morphology and hormonal system. These changes may affect the balance and body stability and can cause discomfort and pain.

Aim of Study: This study was conducted to investigate the effect of arch support on prevention of foot pain during pregnancy.

Material and Methods: Sixty pregnant women shared in this study. They were selected randomly from Al-Zahraa University Hospital, Al-Azhar University, in Cairo. Their ages were ranged from 20 to 30 years old and their BMI were less than $30 \mathrm{Kg} / \mathrm{m}$. They were divided randomly into two groups equal in number: Group A (control group) which consisted of 30 pregnant women received no intervention and group $\mathrm{B}$ (study group) which consisted of 30 pregnant women wore arch support from the beginning of 2 nd trimester till 6 weeks postpartum. All women in both groups were evaluated through Navicular Index (NI) and Visual Analog Scale (VAS) before treatment (at the beginning of the 4 th month of pregnancy), at the end of third trimester (at the end of 9 th month of pregnancy) and at the end of puerperium (six weeks postpartum).
\end{abstract}

Results: Results of this study revealed that there was no statistically significant difference in navicular index between both groups (A and B) at the 4 th month of pregnancy and after six weeks postpartum ( $p=0.403)$. But there was statistically significant difference between them at ${ }^{\text {th }}$ month of pregnancy in favour of group B (decrease) $(p=0.002)$. There was a statistically significant difference in VAS between both groups at both 9 th month of pregnancy and 6 weeks postpartum in favour of group B (decrease) $(p=0.001)$.

Conclusion: It can be concluded that wearing arch support prevents foot pain during pregnancy.

Key Words: Arch supportn - Foot pain - Pregnancy.

Correspondence to: Dr. Mohamed A. Awad, The Department of Physical Therapy for Obstetrics and Gynaecology, Faculty of Physical Therapy, Cairo University, Egypt

\section{Introduction}

PREGNANCY is a normal physiologic state that is characterized by growth of both the mother and fetus. There are extensive biomechanical, physiological and structural changes to provide a suitable environment for nutrition, growth and development of the fetus [1]

During pregnancy women experience several changes in the body's physiology, morphology and hormonal system. These changes may affect the balance and body stability and can cause discomfort and pain [2]

The combination of ligamentous laxity in the arch, increased body mass and the shift in the Center of Pressure (COP) towards the posterior part of the foot during pregnancy may contribute to change in length of the ligaments supporting the arch, leading to loss of arch height. In turn, changes in foot biomechanics that occur with changes in the foot structure can alter the normal control of forces propagating from the foot to more proximal lower limb joints and spine and may contribute to pain in the feet, knees and hips [3]

It is plausible that increased Body Mass Index (BMI) may be a risk factor for plantar heel pain, as individuals with increased BMI experience higher vertical forces under the heel during gait, leading to higher internal stresses within the heel, which may lead to damage of soft tissue structures and the development of symptoms [4].

Women are disproportionately affected by musculoskeletal disorders. Parous women appear to be at particularly elevated risk for structural and functional changes in the lower limbs. The combination of increased weight on joints with potentially greater laxity during pregnancy could lead to struc- 
tural changes in feet. Although arches may become lax during pregnancy $[\mathbf{s}$

There is prominent increased postural sway in anterior-posterior direction in this period it is believed that based on the observed pressure changes, foot pain in pregnancy due to changes in body mass and body distribution may be relieved by exercise and shoewear modifications [6]

A foot orthosis, or arch support, is a custom molded device made from a variety of materials ranging from rigid plastic to soft foams. It is designed to support the arches of the foot and redistribute the weight to different areas to prevent excessive pressure. It may also correct mild alignment problems. These custom foot orthoses are designed to give support to the arch area of the foot. Sometimes the extra support under the arch is used to relieve stress on stretched tendons, support fractured bones, or take weight off tender areas. Other times the orthoses are used to influence the roll of the foot. They are also designed to resist an arch that is rolling over. Ultimately, the orthoses can do several of these functions at once [7].

Studies conducted using cadaver specimens suggest that foot orthoses can reduce the strain in the plantar fascia during static loading, reduce the collapse of the medial longitudinal arch, and reduce elongation of the foot associated with pronation [8]

Use of appropriate arch supports is necessary, a semirigid orthosis with a medial arch support no higher than five-eighths of an inch can be utilized to help to limit excess pronation [9]. Arch supports have been found to relieve the end of the day pain by supporting the medial longitudinal arch and, thus, preventing over stretches during prolonged weight bearing [10].

\section{Material and Methods}

Sixty pregnant women shared in this study. They were selected randomly from Al-Zahraa University Hospital, Al-Azhar University, Cairo. Their ages were ranged between 20-30 years. Their body mass index was less than $30 \mathrm{Kg} / \mathrm{m}^{2}$. All women were at the begning of the second trimester, primipara, did not recive any other treatment method for foot pain and were working women. Women with history of bone diseases, acute disease, acute stage of inflammation, epilepsy disease, nonworking women, chronic diseases affecting collagen metabolism or had surgeries that might affect their walking are excluded from the study. Duration of the study was six months from 15 March to 15
September 2017. All women were devided randomly into 2 equal groups (A \& B). Group A (control group): It consisted of 30 pregnant women, they had received no intervention. Group B (study group): It consisted of 30 pregnant women, they wore arch support from the beginning of 2 nd trimester till 6 weeks postpartum. Design of the study was pre-test, post-test two groups randomized expremental study.

\section{I- Material:}

1- Informed consent form.

2- Standard weight and height scale.

3- Tape measurement.

4- Visual Analog Scale (VAS).

5- Navicular Index (NI).

6- Arch support.

\section{II- Procedures:}

A full history was taken from each woman before starting this study according to the items of the recording data sheet each woman assigened in informed concent form (Appendix I). All women were given a full explanation of the protocol of the study and consent form were signed for each women before participating in the study.

\section{A- Evaluation procedures:}

The procedure was carefully and clearly explained to all women.

All women in both groups were evaluated at beginning of 2 nd trimester (at the beginning of the $4^{\text {th }}$ month), at the end of third trimester (at the end of $9^{\text {th }}$ month) and at the end of puerperium (six weeks postpartum).

1-Assessment of BMI: Weight and height were measured while the woman wearing a thin layer of clothes to calculate the BMI for each woman in both groups according to the following equation: BMI $\left(\mathrm{Kg} / \mathrm{m}^{2}\right)=$ weight $(\mathrm{kg}) /$ height $2\left(\mathrm{~m}^{2}\right)$.

2- Visual Analogue Scale (VAS): The Visual Analogue Scale (VAS) is a measurement instrument that tries to measure a characteristic or attitude that is believed to range across a continuum of values and cannot easily be directly measured. It measures the amount of pain that a patient feels [11]. The VAS used in this study was a horizontal line, $100 \mathrm{~mm}$ in length, anchored by word descriptors at each end (i.e., no pain; worst pain possible). A higher score correlated with higher pain intensity and a lower score correlated with lower pain intensity. Women were asked to select the point on the scale that best repre- 
sents the perceived level of pain. Women marked on the line the point that they felt represented their current pain state.

3- Navicular Index (NI): It was used to evaluate the correlation of navicular bone height with most often used angles, heel valgus and a foot print in order to simplify the procedure for the measurment of the medial longitudinal arch of the foot. With the patient standing with equal weight distrepution on both feet, the midpoint of the medial malleolus, the navicular tuberosity, and the most medial prominence of the first

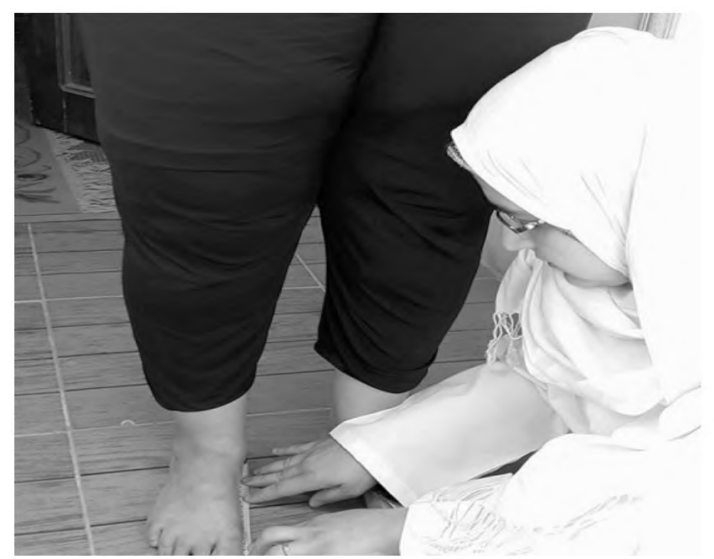

Fig. (1): Measuring length of medial longitudinal arch to calculate NI.

\section{B- Treatment procedures:}

Group A (control group): It consisted of 30 pregnant women, they received no intervention.

Group B (study group): It consisted of 30 pregnant women, they wore arch support from the beginning of 2 nd trimester till 6 weeks postpartum.

\section{Statistical analysis:}

Results are expressed as mean \pm standard deviation or median (minimum-maximum). Test of normality, Kolmogorov-Smirnov test, was used to measure the distribution of data measured pretreatment. Accordingly, comparison between variables in the two groups was performed using either unpaired $t$-test or Mann Whitney test whenever it was appropriate.

In normally distributed data, comparison between variables measured at different time of metatarsal head are identified using palpation and marked with a pen forming 3 points in which the navicular tuberosity acting as the axis point. The distance between midpoint of the medial malleolus and the most medial prominence of the first metatarsal head was the length of medial longitudinal arch Fig. (1) and the distance between the ground and the navicular tuberosity was the navicular height Fig. (2). The navicular index was calculated by dividing length of medial longitudinal arch with navicular height [12]

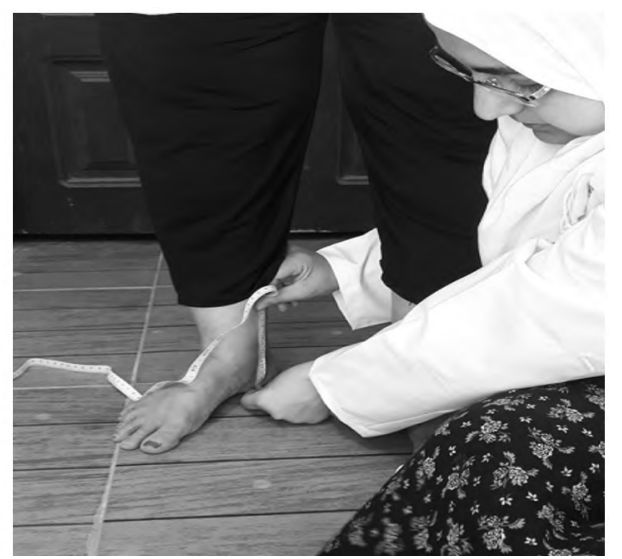

Fig. (2): Measuring navicular height to calculate NI.

measurements in the same group was performed using repeated measures ANOVA test followed by Bonferroni test.

In not normally distributed data, comparison between variables measured at different time of measurements in the same group was performed using Friedman ANOVA test followed by Wilcoxon Signed Ranks test.

Statistical Package for Social Sciences (SPSS) computer program (Version 19 windows) was used for data analysis. $p$-value $\leq 0.05$ was considered significant.

\section{Results}

I- Physical characteristics of the subjects in both groups (age): There was no statistical significant difference between both groups $(t$-value $=1.683$; $p$-value $=0.098)($ Table 1$)$.

Table (1): Comparison between mean values of age in both groups.

\begin{tabular}{lcccc}
\hline & Control $(\mathrm{n}=30)$ & Study $(\mathrm{n}=30)$ & $t$-value & $p$-value \\
\hline Age (yrs.) & $24.15 \pm 1.58$ & $24.90 \pm 1.86$ & -1.683 & $0.098(\mathrm{NS})$ \\
\hline
\end{tabular}


II- BMI:

Between groups:

At the ${ }^{4 \text { th }}$ month of pregnancy, at the 9 th month of pregnancy and after six weeks postpartum, there was no statistical significant difference between both groups (A \& B) $(t=-0.525,-0.586$ and -0.576 respectivly), ( $p=0.602,0.560$ and 0.567 respectivly) (Table 2).

Table (2): Comparison between mean values of BMI in both groups measured during pregnancy (at the 4 th and 9 th months) and after 6 weeks postpartum.

\begin{tabular}{lcccc}
\hline & Control $(\mathrm{n}=30)$ & Study $(\mathrm{n}=30)$ & $t$-value & $p$-value \\
\hline 4th month of pregnancy & $24.90 \pm 3.91$ & $25.40 \pm 3.50$ & -0.525 & 0.602 (NS) \\
9th month of pregnancy & $31.96 \pm 4.09$ & $32.55 \pm 3.73$ & -0.586 & 0.560 (NS) \\
6th weeks postpartum & $27.55 \pm 3.93$ & $28.11 \pm 3.48$ & -0.576 & 0.567 (NS) \\
\hline
\end{tabular}

III- Navicular Index (NI):

\section{A- Within groups:}

Group A: There was a statistical significant difference between 4 th and 9 th month of pregnancy and 6 weeks postpartum $(\mathrm{F}=233.529 ; p=0.001)$. The mean value of NI at the 9 th month of pregnancy was significantly increased when compared with its corresponding value measured at the $4^{\text {th }}$ month of pregnancy and after 6 weeks postpartum ( $p=$ $0.001)$. At the other hand the mean value of NI measured after 6 weeks postpartum was returned to its baseline measured at the 4 th months of pregnancy (Table 3). The percentage of increase in NI at the 9 th month of pregnancy was $(27.46 \%)$.

Table (3): Comparison between mean values of navicular index measured during pregnancy (at the 4 th and 9th months) and after 6 weeks postpartum in group A.

\begin{tabular}{lccccc}
\hline & $\begin{array}{c}\text { 4th months } \\
\text { of pregnancy }\end{array}$ & $\begin{array}{c}\text { 9th months } \\
\text { of pregnancy }\end{array}$ & $\begin{array}{c}6^{\text {th }} \text { weeks } \\
\text { postpartum }\end{array}$ & F-value & $p$-value \\
\hline Mean \pm SD & $3.35 \pm 0.70$ & $4.27 \pm 0.93$ & $3.35 \pm 0.70$ & 233.529 & $0.001(\mathrm{~S})$ \\
Mean difference & - & 0.92 & 0.0 & & \\
$\%$ change & - & $27.46 \uparrow \uparrow$ & 0.0 & & \\
$p$-value vs. 4th month of pregnancy & - & $0.001(\mathrm{~S})$ & & & \\
$p$-value vs. 9th month of pregnancy & - & & $0.001(\mathrm{~S})$ & & \\
\hline
\end{tabular}

Group B: There was a statistically significant difference between $4^{\text {th }}, 9$ th and 6 weeks postpartum $(\mathrm{F}=24.967 ; p=0.001)$. The mean value of NI at the $9^{\text {th }}$ month of pregnancy was significantly increased when compared with its corresponding value measured at the 4th month of pregnancy and after 6 weeks postpartum $(p=0.001)$. At the other hand the mean value of NI measured after 6 weeks postpartum was returned to its baseline measured at the 4 th months of pregnancy (Table 4). The percentage of increase in NI at the 9 th month of pregnancy was $(3.15 \%)$.

Table (4): Comparison between mean values of navicular index measured during pregnancy (at the 4 th and 9 th months) and after 6 weeks postpartum in group B.

\begin{tabular}{|c|c|c|c|c|c|}
\hline & $\begin{array}{l}4 \text { th months } \\
\text { of pregnancy }\end{array}$ & $\begin{array}{l}9 \text { th months } \\
\text { of pregnancy }\end{array}$ & $\begin{array}{l}6^{\text {th }} \text { weeks } \\
\text { postpartum }\end{array}$ & F_value & $p_{-}$value \\
\hline Mean \pm SD & $3.49 \pm 0.62$ & $3.60 \pm 0.64$ & $3.49 \pm 0.62$ & 24.967 & $0.001(\mathrm{~S})$ \\
\hline Mean difference & - & 0.11 & 0.0 & & \\
\hline$\%$ change & - & $3.15 \uparrow \uparrow$ & 0.0 & & \\
\hline$p$-value vs. 4 th month of pregnancy & - & $0.001(\mathrm{~S})$ & & & \\
\hline$p$-value vs. 9 th month of pregnancy & - & & $0.001(\mathrm{~S})$ & & \\
\hline
\end{tabular}

B- Between groups: At the 4 th months of pregnancy and after six weeks postpartum, there was no statistically significant difference between both groups (A \& B) $(t=-0.842$ and $p=0.403)$. At the
9 th months of pregnancy, there was a statistically significant difference between both groups (A \& B) in favor of group B (decrease) $(t=3.257 ; p=$ 0.002) (Table 5); Fig. (3). 
Table (5): Comparison between mean values of navicular index in both groups measured during pregnancy (at the $4^{\text {th }}$ and $9^{\text {th }}$ months) and after 6 weeks postpartum.

\begin{tabular}{lcccc}
\hline & Control $(\mathrm{n}=30)$ & Study $(\mathrm{n}=30)$ & $t$-value & $p$-value \\
\hline $4^{\text {th }}$ month of pregnancy & $3.35-\} 0.70$ & $3.49-\} 0.62$ & -0.842 & 0.403 (NS) \\
$9^{\text {th }}$ month of pregnancy & $4.27-\} 0.93$ & $3.60-\{0.64$ & 3.257 & 0.002 (S) \\
$6^{\text {th }}$ weeks postpartum & $3.35-\} 0.70$ & $3.49-\{0.62$ & -0.842 & 0.403 (NS) \\
\hline
\end{tabular}

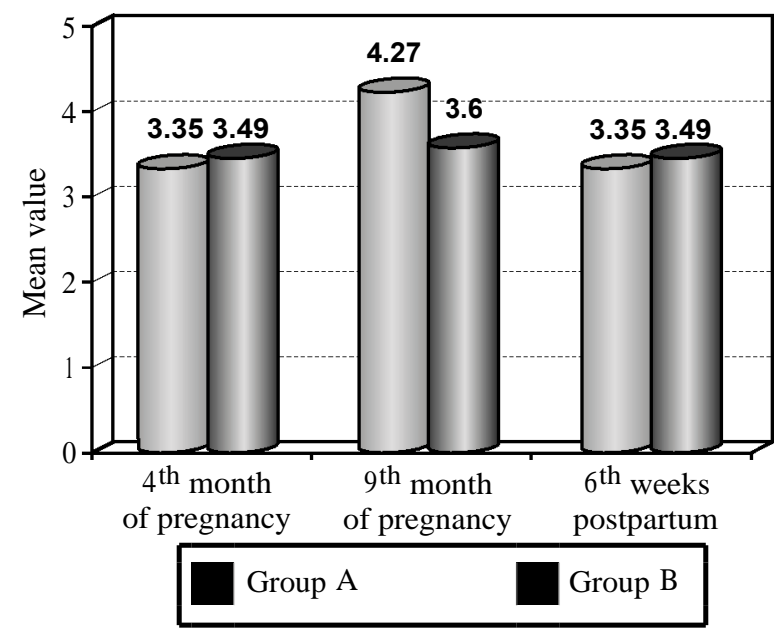

Fig. (3): Comparison between mean values of NI in both groups measured during pregnancy (at the $4^{\text {th }}$ and $9^{\text {th }}$ months) and after 6 weeks postpartum.
IV- Visual Analoge Scale (VAS):

\section{A- Within groups:}

Group A: There was a statistically significant difference between $4^{\text {th }}, 9^{\text {th }}$ month and 6 weeks post partum (Chi square value $=47.113 ; p=0.001$ ). The median value of VAS at the 9 th month of pregnancy was significantly increased when compared with its corresponding value measured at the $4^{\text {th }}$ month of pregnancy $(\mathrm{Z}=-4.853 ; p=0.0 .001)$. There was no statistical significant difference between the median value of VAS measured at the $4^{\text {th }}$ month of pregnancy and 6 weeks postpartum $(\mathrm{Z}=-0.141 ; p=0.888)$. The median value of VAS measured at 6 weeks postpartum was significantly decreased when compared with the median value of VAS measured at $9^{\text {th }}$ month of pregnancy $(\mathrm{Z}=$ 4.809; $p=0.001$ ) (Table 6).

Table (6): Comparison between median values of pain measured during pregnancy (at $4^{\text {th }}$ and $9^{\text {th }}$ months) and after 6 weeks postpartum in group A.

\begin{tabular}{|c|c|c|c|c|c|}
\hline & $\begin{array}{l}4^{\text {th }} \text { months } \\
\text { of pregnancy }\end{array}$ & $\begin{array}{l}9^{\text {th }} \text { months } \\
\text { of pregnancy }\end{array}$ & $\begin{array}{l}6^{\text {th }} \text { weeks } \\
\text { postpartum }\end{array}$ & $t$-value & $p$-value \\
\hline Median (minimum-maximum) & $2.0(0.0-4.0)$ & $6.0(2.0-9.0)$ & $2.0(0.0-5.0)$ & 47.113 & $0.001(\mathrm{~S})$ \\
\hline$p$-value vs $4^{\text {th }}$ month of pregnancy & - & $\begin{array}{l}\mathrm{Z}=-4.853 \& \\
p=0.001(\mathrm{~S})\end{array}$ & $\begin{array}{l}\mathrm{Z}=-0.141 \& \\
p=0.888(\mathrm{NS})\end{array}$ & & \\
\hline$p$-value vs $9^{\text {th }}$ month of pregnancy & - & - & $\begin{array}{l}Z=-4.809 \& \\
p=0.001(S)\end{array}$ & & \\
\hline
\end{tabular}

Group B: There was a statistically significant difference between $4^{\text {th }}, 9^{\text {th }}$ month and 6 weeks postpartum (Chi square value $=45.398 ; p=0.001$ ). The median value of VAS measured at both the $9^{\text {th }}$ month of pregnancy and at 6 weeks postpartum were significantly decreased when compared with there corresponding value measured at the $4^{\text {th }}$ month of pregnancy $(\mathrm{Z}=-4.441 ; p=0.0 .001)(\mathrm{Z}=$ $-4.461 ; p=0.001)$ respectively. On the other hand there was no statistical significant difference between the median value of VAS measured at the $9^{\text {th }}$ month of pregnancy and at 6 weeks postpartum $(\mathrm{Z}=-0.632 ; p=0.527)$ (Table 7).

\section{B- Between groups:}

At the $4^{\text {th }}$ months of pregnancy, there was no statistical significant difference between both groups (A and $B)(Z=-0.898 ; p=0.369)$. At the $9^{\text {th }}$ months of pregnancy and after six weeks postpartum, there was a statistically significant difference between both groups (A and B) in favor of group $B$ (decrease) $(\mathrm{Z}=-6.916,-5.924$ respectively and $p=0.001$ ). (Table 8); Fig. (4).

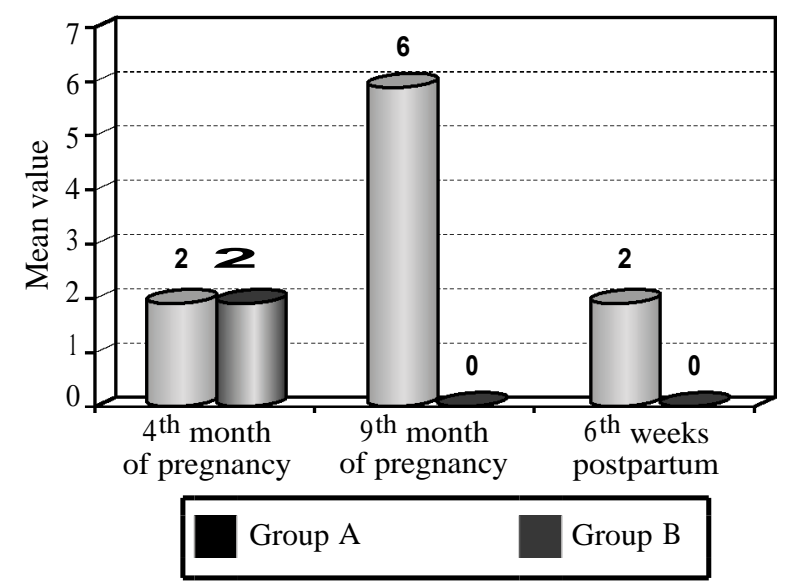

Fig. (4): Comparison between median values of VAS in both groups measured during pregnancy (at the $4^{\text {th }}$ and $9^{\text {th }}$ months) and after 6 weeks postpartum. 
Table (7): Comparison between median values of VAS measured during pregnancy (at 4 th and 9th months) and after 6 weeks postpartum in group B.

\begin{tabular}{|c|c|c|c|c|c|}
\hline & $\begin{array}{l}\text { 4th months } \\
\text { of pregnancy }\end{array}$ & $\begin{array}{l}\text { 9th months } \\
\text { of pregnancy }\end{array}$ & $\begin{array}{l}\text { 6th weeks } \\
\text { postpartum }\end{array}$ & $t$-value & $p$-value \\
\hline Median (minimum-maximum) & $2.0(0.0-4.0)$ & $0.0(0.0-2.0)$ & $0.0(0.0-1.0)$ & 45.398 & $0.001(\mathrm{~S})$ \\
\hline$p$-value vs. 4 th month of pregnancy & - & $\begin{array}{l}\mathrm{Z}=-4.441 \& \\
p=0.001(\mathrm{~S})\end{array}$ & $\begin{array}{l}\mathrm{Z}=-4.461 \& \\
p=0.001(\mathrm{~S})\end{array}$ & & \\
\hline$p$-value vs. 9 th month of pregnancy & - & - & $\begin{array}{l}\mathrm{Z}=-0.632 \& \\
p=527(\mathrm{NS})\end{array}$ & & \\
\hline
\end{tabular}

Table (8): Comparison between median values of VAS in both groups measured during pregnancy (at the 4 th and 9 th months) and after 6 weeks postpartum.

\begin{tabular}{lcccc}
\hline & Control $(\mathrm{n}=30)$ & Study $(\mathrm{n}=30)$ & Z-value & $p$-value \\
\hline 4th month of pregnancy & $2.0(0.0-4.0)$ & $2.0(0.0-4.0)$ & -0.898 & $0.369(\mathrm{NS})$ \\
9th month of pregnancy & $6.0(2.0-9.0)$ & $0.0(0.0-2.0)$ & -6.916 & $0.001(\mathrm{~S})$ \\
6th weeks postpartum & $2.0(0.0-5.0)$ & $0.0(0.0-1.0)$ & -5.924 & $0.001(\mathrm{~S})$ \\
\hline
\end{tabular}

\section{Discussion}

Pregnancy introduces physical and psychological changes into life of women that may affect their individual perception of quality of life. Many women feel unattractive and heavy, and may also have difficulty with some movements and in performing routine activities [13].

Pregnancy appears to be associated with loss of arch height and the first pregnancy may be the most significant. These changes in the feet could contribute to the increased risk for musculoskeletal disorders in women [5]

This study was conducted to investigate the effect of arch support on prevention of foot pain during pregnancy. Sixty pregnant women shared in this study. They were selected randomly from Al-Zahraa University Hospital, Al-Azhar University, in Cairo. Their ages were ranged from 20 to 30 years old and their BMI were less than $30 \mathrm{Kg} / \mathrm{m}^{2}$. They were divided randomly into two groups equal in number: Group A (control group) which consisted of 30 pregnant women received no intervention and group B (study group) which consisted of 30 pregnant women wore arch support from the beginning of 2 nd trimester till 6 weeks postpartum.

All women in both groups were evaluated through Navicular Index (NI) and Visual Analog Scale (VAS) before treatment (at the beginning of the 4 th month of pregnancy), at the end of third trimester (at the end of 9 th month of pregnancy) and at the end of puerperium (six weeks postpartum).

Results of this study revealed that there was no statistically significant difference in navicular index between both groups (A and B) at the 4 th month of pregnancy and after six weeks postpartum $(p=0.403)$. But there was statistically significant difference between them at ${ }^{9}$ month of pregnancy in favour of group B (decrease) ( $p=0.002$ ).

There was a statistically significant difference in VAS between both groups at both 9 th month of pregnancy and 6 weeks postpartum in favour of group B (decrease) $(p=0.001)$.

Hormonal changes in women are quite variable throughout pregnancy. However, the relaxin hormone may have a more decisive role in the mechanics of movement as it provides greater ligament laxity in the pelvis and on the peripheral joints. The concentration peak of relaxin occurs around the 12 th week of gestation, which means that there is enough time to act in osteoarticular structures until the end of pregnancy [2] .

Women's feet change during pregnancy owing to hormonal and anatomical changes, thus having a strong influence on the decrease in their quality of life during pregnancy. The foot of the pregnant woman tends to flatten during gestational weeks 12 to 34 , taking a more pronated posture, and the anthropometric changes in late pregnancy result in increases in foot length and forefoot width, changes that seem to be moderate [14].

Studies have reported an increase in foot length, width and volume during pregnancy [15]. Therefore, disruption of the interaction between skeletal and musculotendinous and ligamentous structures through loss of arch height may predispose to painful musculoskeletal conditions [5].

The combination of ligamentous laxity in the arch, increased body mass and the shift in the 
Center of Pressure (COP) towards the posterior part of the foot during pregnancy may contribute to change in length of the ligaments supporting the arch, leading to loss of arch height. In turn, changes in foot biomechanics that occur with changes in the foot structure can alter the normal control of forces propagating from the foot to more proximal lower limb joints and spine and may contribute to pain in the feet, knees and hips [3].

The result of this study agreed with those of [16] who studied the outcomes of magnetic foil placed in the heel of firm molded insoles against firm molded insoles without magnetic foil. Subjective reports were evaluated at baseline and after four weeks of treatment using subscales of the Functional Foot Index (FFI). At the conclusion of the study both groups noted significant improvements in foot function. When the two groups were compared, statistical significance was not noted between the groups, indicating that the magnetic foil offered no benefit over the insole alone.

The results of this study are supported by [17] who found that arch supports have been found to relieve the end of the day pain by supporting the medial longitudinal arch and, thus, preventing overstretches during prolonged weight bearing.

The result of this study agreed with those of [18]who studied the effect of custom made orthoses versus over the counter arch supports versus tension night splints on 255 patients. A three-arm trial was conducted at which, the first group received custom made orthoses made from $5 \mathrm{~mm}$ Polydurplastic material; the second group received over-thecounter-arch supports (Foot Soldiers); the third group received a posterior tension night splint at 5 degrees of ankle dorsi flexion. He did not detect a statistical difference between the interventions.

The result of this study agreed with those of [19] who found that foot orthoses are frequently utilized as a component of the conservative management plan for foot pain. The justification given for the use of foot orthoses is to decrease abnormal foot pronation that is thought to cause increased stress on the medial band of the plantar fascia.

The results of this study disagreed with the results of [20] who studied the effect of steroid injections and orthosis versus steroid injections alone versus orthosis alone on 80 patients with heel pain. Patients received either an anti-pronatory insole or a steroid injection of triamcinolone hexacetonide (Lederspan) $20 \mathrm{mg}$ mixed with $2 \%$ lignocaine or both. The results showed that the patients who received steroid injections alone had the greatest improvement in pain levels compared with a pad and a combination of the pad and injection.

\section{Conclusion:}

On the basis of the data obtained in the present study, we conclude that wearing arch support prevents foot pain during pregnancy.

\section{References}

1- ARTAL R., CLAPPE J. and VIGIL D.: Exercise during pregnancy. Am. Collage of Sports Medicine, 1-3, 2000.

2- BUTLER E., DRUZIN M. and SULLIVAN E.: Gait adaptations in adulthood: Pregnancy, aging, and alcoholism. Textbook. ${ }^{3 r d}$ edition. Philadelphia, Pa, USA: Lippincott Williams \& Wilkins, pp. 131-48, 2006.

3- ERHART J., MUNDERMANN A., MUNDERMANN L. and ANDRIACCHI T.: Predicting changes in knee adduction moment due to load-altering interventions from pressure distribution at the foot in healthy subjects. J. Biomech., 41 (14): 2989-94, 2008.

4- HILLS A., HENNIG E., McDONALD M. and BAR-OR O.: Plantar pressure differences between obese and nonobese adults: A biomechanical analysis. International Journal of Obesity and Related Metabolic Disorders, 25: 1674-9, 2001

5- SEGAL A., BOYER R., TERAN-YENGLE P., GLASS N. and HILLSTROM J.: Pregnancy Leads to Lasting Changes in Foot Structure. Am. J. Phys. Med. Rehabil., 92 (3): 232-40, 2013.

6- KARADAG-SAYGI E., UNLU-OZKAN F. and BASGUL A.: Plantar pressure and foot pain in the last trimester of pregnancy. Foot Ankle Int., 31 (2): 153-7, 2010.

7- COPPARD B.M. and LOHMAN H.: Introduction to splinting. A clinical reasoning \& proplem-solving apporoach. Chapter 17 lower extremity orthotics. Third edition, pp. 395-6, 2008.

8- KITAOKA H.B., LUO Z.P., KURA H. and AN K.N.: Effect of foot orthoses on 3-dimensional kinematics of flatfoot: A cadaveric study. Arch. Phys. Med. Rehabil., 83: 876-9, 2002.

9- LANDORF K., KEENAN A. and HERBERT R.: Effectiveness of different types of foot orthoses for the treatment of plantar fasciitis. Journal of the American Podiatric Association, 94 (6): 542-49, 2004.

10- MCPOIL T. and CORNWALL M.: The effect of foot orthoses on transverse tibial rotation during walking. Journal of the American Podiatric Medical Association, 90: 2-11, 2000.

11-GOULD D., KELLY D., GOLDSTONE L. and GAMMON J.: Visual analogue scale. Journal of Clinical Nursing, 10: 697-706, 2001.

12- ROTH S., ROTH A., JOTANOVIC Z. and MADAREVIC T.: Navicular index for differentiation of flatfoot from normal. Foot International Orthopaedics, 37 (6): 1107 $12,2013$.

13- GRANATH A., HELLGREN M. and GUNNARSSON R.: Water aerobics reduces sick leave due to low back 
pain during pregnancy. J. Obste. Pt. Gynecol. Neonatal. Nurs., 35 (4): 465, 2006.

14- GIJON-NOGUERON G., GAVILAN-DIAZ M., VALLEFUNES V., JIMENEZ-CEBRIAN A., CERVERA-MARIN J. and MORALES-ASENCIO J.: Anthropometric foot changes during pregnancy: A pilot study. J. Am. Podiatr. Med. Assoc., 103 (4): 314-21, 2013.

15- WETZ H., HENTSCHEL J., DRERUP B., KIESEL L., OSADA N. and VELTMANN U.: Changes in shape and size of the foot during pregnancy. Orthopade, 35 (11): 1124, 6-30, 2006.

16- CASELLI M., CLARK N., LAZARUS S., VELEZ Z. and VENEGAS L.: Evaluation of magnetic foil and PPT insoles for treatment of heal pain. Journal of the American Podiatric Association; Appl. Ergon., (46): 212-7, 1997.

17- MACPOIL T.G., MARTIN R.L., CORNWALL M.W., WUKICH D.K., IRRGANG J.I. and JOSEPH J.G.: Heel
Pain-Plantar Fasciitis Clinical Practice Guidelines Linked to the International Classification of Functioning, disability, and health from, the Orthopaedic Section of the American Physical Therapy Association, J. Orthop. Sports Phys. Ther., 2008: 38 (4), 2008.

18- MARTIN J., HOSCH J., GOFORTH W., MURFF R., LYNCH D. and ODOM R.: Mechanical treatment of plantar fasciitis. A prospective study. Journal of the American Podiatric Medical Association, 91 (2): 55-62, 2001.

19- IRVING D.B., COOK J.L. and MENZ H.B.: Factors associated with chronic plantar heel pain: A systematic review. J. Sci. Med. Sport, 9: 11-22; discussion 23-4, 2006.

20- KRISS S.: Heel pain: An investigation into its etiology and managment [thesis]. London (UK): Univ. Of westminster, 1990

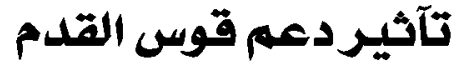 على الوقاية من آلم القلدم آثناء الحمل دامل}

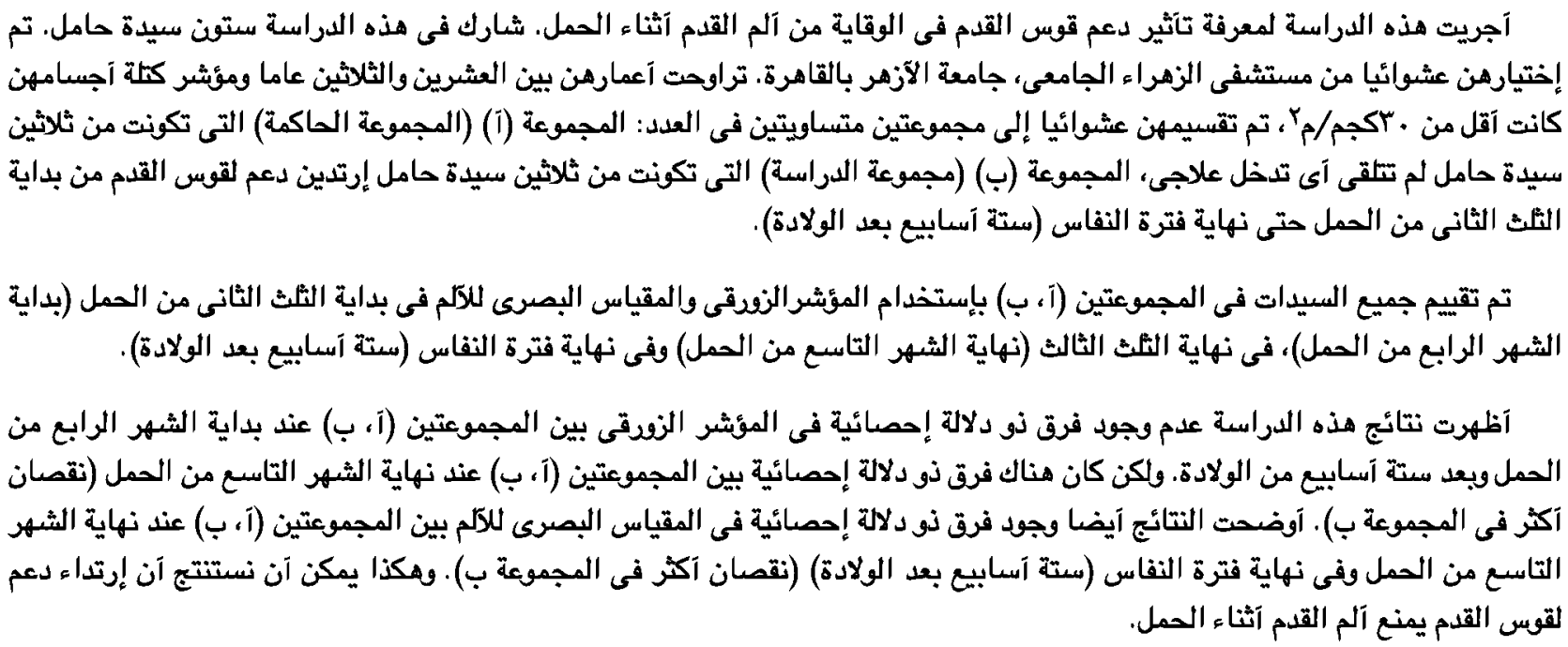

